\title{
MCMV based vaccine vectors expressing full-length viral proteins provide long-term humoral immune protection upon a single-shot vaccination
}

Luka Cicin-Sain ( $\square$ Luka.Cicin-Sain@helmholtz-hzi.de)

Helmholtz Centre for Infection Research https://orcid.org/0000-0003-3978-778X

\section{Yeonsu Kim}

Helmholtz Centre for Infection Research

Xiaoyan Zheng

Helmholtz Centre for Infection Research

Kathrin Eschke

Helmholtz Centre for Infection Research

M. Zeeshan Chaudhry

Helmholtz Centre for Infection Research https://orcid.org/0000-0002-1372-4257

\section{Federico Bertoglio}

Institut für Biochemie, Biotechnologie und Bioinformatik, Technischen Universität Braunschweig

Adriana Tomic

University of Oxford

Markus Hoffmann

Georg-August-University Göttingen https://orcid.org/0000-0003-4603-7696

\section{Yotam Bar-On}

Rappaport Faculty of Medicine, Technion - Israel Institute of Technology

Julia Boehme

Helmholtz-Centre for Infection Research

\section{Dunja Bruder}

Otto-von-Guericke University

\section{Thomas Ebensen}

Helmholtz Centre for Infection Research

\section{Linda Brunotte}

University Hospital Muenster

\section{Stephan Ludwig}

Institute of Virology (IVM), Westfaelische Wilhelms Universitaet, Muenster, Nordrhein-Westfalen, 48149 https://orcid.org/0000-0003-4490-3052

\section{Martin Messerle}

Hannover Medical School (MHH) 


\section{Carlos Guzmán}

Helmholtz Centre for Infection Research

Ofer Mandelboim

The Hebrew University Hadassah Medical School

\section{Michael Hust}

Technische Universität Braunschweig https://orcid.org/0000-0003-3418-6045

\section{Stefan Pöhlmann}

German Primate Center - Leibniz Institute for Primate Research https://orcid.org/0000-0001-6086-9136

Stipan Jonjic

Univesity of Rijeka, Faculty of Medicine https://orcid.org/0000-0001-5003-3108

\section{Article}

Keywords: Cytomegalovirus, Antigen-specific CD8+ T Cells, Neutralizing Antibody Responses, Memory T Cells

Posted Date: June 3rd, 2021

DOI: https://doi.org/10.21203/rs.3.rs-566785/v1

License: (c) (1) This work is licensed under a Creative Commons Attribution 4.0 International License. Read Full License

Version of Record: A version of this preprint was published at Cellular \& Molecular Immunology on January 7th, 2022. See the published version at https://doi.org/10.1038/s41423-021-00814-5. 
MCMV based vaccine vectors expressing full-length viral proteins provide long-

2 term humoral immune protection upon a single-shot vaccination

3 Yeonsu Kim ${ }^{1 *}$, Xiaoyan Zheng ${ }^{1 *}$, Kathrin Eschke ${ }^{1 *}$, M. Zeeshan Chaudhry ${ }^{1 *}$, Federico Bertoglio ${ }^{2}$,

4 Adriana Tomic ${ }^{3}$, Markus Hoffmann ${ }^{4 a, 4 b}$, Yotam Bar-On ${ }^{5}$, Julia Boehme ${ }^{6}$, Dunja Bruder ${ }^{6}$, Thomas

5 Ebensen ${ }^{7}$, Linda Brunotte ${ }^{8}$, Stephan Ludwig $^{8}$, Martin Messerle ${ }^{9}$, Carlos Guzman ${ }^{7}$, Ofer

6 Mandelboim $^{10}$, Michael Hust ${ }^{2}$, Stefan Pöhlmann ${ }^{4 a, 4 b}$, Stipan Jonjic ${ }^{3}$, Cicin-Sain-Luka ${ }^{1,11,12 †}$

7 1. Department for Immunology of Clinically Relevant Infections, Helmholtz Centre for $8 \quad$ Infection Research (HZI), Braunschweig, Germany

9 2. Department of Biotechnology, Institut für Biochemie, Biotechnologie und Bioinformatik, Technischen Universität Braunschweig, Braunschweig, Germany

3. Oxford Vaccine Group, University of Oxford, UK.

4. a: Infection Biology Unit, German Primate Center, Göttingen, Germany; b: Faculty of Biology and Psychology, Georg-August-University Göttingen, Göttingen, Germany

5. Department of Immunology, Rappaport Faculty of Medicine, Technion - Israel Institute of Technology, Haifa, Israel.

6. Infection Immunology, Institute for Medical Microbiology and Hospital Hygiene, Health

Campus Immunology, Infectiology and Inflammation, Otto-von-Guericke-University Magdeburg, Magdeburg, Germany; Immune Regulation, Helmholtz Centre for Infection Research, Braunschweig, Germany

7. Department of Vaccinology and Applied Microbiology, Helmholtz Centre for Infection Research, Braunschweig, Germany

8. Institute of Virology, Medical University Münster, Germany

9. Institute of Virology, Hannover Medical School (MHH), Hannover, Germany

10. The Lautenberg Center for General and Tumor Immunology, the Faculty of Medicine, IMRIC, The Hebrew University Medical School, Jerusalem 
11. German Centre for Infection Research (DZIF), Hannover-Braunschweig Site, Germany

12. Centre for Individualized Infection medicine (CiiM), a joint venture of $\mathrm{HZI}$ and $\mathrm{MHH}$, Hannover, Germany

* these authors have contributed equally

† Corresponding author: luka.cicin-sain@helmholtz-hzi.de

\section{Author Contributions}

32 Study conception and design: Y.K., X.Z, K.E., L.C.-S. Methodology: Y.K., K.E., M.Z.C., F.B., 33 M.Ho., X.Z.; Analysis and Interpretation of Results: Y.K. M.Ho. and X.Z. Investigation: Y.K., X.Z., M.Z.C., K.E., F.B., M.Ho., A.T., Y.B.-O., J.B., T.E.; Original Draft Preparation: Y.K. and X.Z.; Draft Review \& Editing: Y.K. and L.C.-S.; Final edition: Y.K., M.Z.C., and L.C.-S.; Supervision: D.B., C.G.,O.M., M.Hu., S.P., S.J. and L.C.-S.; Resources, L.B., S.L., and M.M. All authors reviewed the results and approved the final version of the manuscript.

\section{Abstract}

Global pandemics by influenza or coronaviruses cause severe disruptions to the public health and lead to severe morbidity and mortality. Vaccines against these pathogens remain a medical need. CMV (cytomegalovirus) is a $\beta$-herpesvirus that induces uniquely robust immune responses, where outstandingly large populations of antigen-specific CD8 ${ }^{+} \mathrm{T}$ cells are maintained for a lifetime. Hence, CMV has been proposed and investigated as a novel vaccine vector expressing antigenic peptides or proteins to elicit protective cellular immune responses against numerous pathogens. We generated two recombinant murine CMV (MCMV) vaccine vectors expressing the

47 hemagglutinin $(\mathrm{HA})$ of influenza $A$ virus $\left(\mathrm{MCMV}^{\mathrm{HA}}\right)$ or the spike protein of the severe acute respiratory syndrome coronavirus $2\left(\mathrm{MCMV}^{\mathrm{S}}\right)$. A single shot of MCMVs expressing either viral protein induced potent neutralizing antibody responses, which strengthened over time. 
50 Importantly, $\mathrm{MCMV}^{\mathrm{HA}}$ vaccinated mice were protected from illness following challenge with the

51 influenza virus, and we excluded that this protection was due to effects of memory $\mathrm{T}$ cells.

52 Conclusively, we show here that MCMV vectors do not only induce long-term cellular immunity,

53 but also humoral responses that provide long-term immune protection against clinically relevant

54 respiratory pathogens.

\section{Introduction}

57 Severe acute respiratory syndrome coronavirus 2 (SARS-CoV-2) and influenza A virus (IAV) are 58 well-known viruses with a zoonotic origin, causing global pandemics with severe consequences 59 on human health and economies. SARS-CoV-2, which causes coronavirus disease 2019 (COVID-

60 19) pandemics, was first identified in late 2019 in Wuhan, China and has caused a severe global 61 pandemic, which has claimed millions of lives and resulted in severe economic disruption 62 worldwide. Influenza pandemics have also resulted in global disruptions, such as the H1N1

63 Spanish flu in 1918, H3N2 Hong Kong flu in 1968 and H1N1dpm09 Swine flu in 2009, resulting 64 in rapid global spread of this respiratory disease. In addition to these influenza pandemics, seasonal influenza epidemics regularly cause elevated morbidity and mortality in the colder seasons. Both IAV and SARS CoV-2 may cause mild to severe respiratory illnesses, and pose a

67 particular threat to risk groups, such as the elderly or people with pre-existing medical conditions.

68 Both of these respiratory viruses depend on a viral surface protein for attachment and entry into 69 host cells. In case of IAV, the viral hemagglutinin (HA) is the major surface glycoprotein required 70 for cell entry $(1,2)$. Likewise, SARS-CoV-2 uses the spike protein $(S)$ to bind its cellular receptor 71 ACE2 and to drive membrane fusion during virus entry (3-6). Therefore, SARS-CoV-2 S and IAV $72 \mathrm{HA}$ are the main antigenic targets in vaccine formulations against these viruses. 
Numerous efforts are underway to counter COVID-19. There are more than 200 vaccine projects targeting SARS-CoV-2 (7) using formulations that include viral proteins, viral vector vaccines, and mRNA vaccines. Some of these vaccines have already been approved for use in humans or are in advanced clinical trials with promising results. However, all of the candidates raise safety concerns due to side effects like fever, fatigue and headache (8) and most vaccines (or vaccine candidates) require a prime/boost vaccination protocol at multiple week intervals, raising issues of delivery logistics and compliance. Although mRNA vaccines show great promise in the context of the COVID-19 pandemic (9), the experience with their use in clinical settings remains limited (10). Vaccines against influenza target the predicted prevailing strains in each upcoming flu season, and are especially recommended for people at high risk, such as children, elderly and the immunocompromised (11). While influenza vaccines are available, their efficiency is about $19-60 \%$, depending on the flu season $(12,13)$.

Viral vectors do not need adjuvants, because they contain molecular patterns recognized by the innate immune receptors and naturally induce both the cellular and the humoral branch of the adaptive immune response $(14,15)$. Therefore, they are developed by numerous research labs, using a variety of viral vectors, including poxviruses, adenoviruses or herpesviruses, just to name a few (16-25). Among them, cytomegalovirus (CMV) is a highly promising platform for vaccine design, with several advantages and unique features. CMV infection is usually asymptomatic, but the virus persists for life, inducing a strong and durable inflationary CD8+ T-cell response (26-32). The optimal design of CMV-based vaccines is an area of intensive study. Numerous studies on CMV vaccines benefit from powerful CD8 ${ }^{+}$T-cell responses induced by CMV infection. Various experimental CMV vectors expressing single epitopes against diverse pathogens provided immune protection that was based on robust epitope-specific CD8 ${ }^{+}$T-cell response $(18,20,21$, 28, 33-37). In alignment with this strategy, boosting or maintaining strong CD8+ ${ }^{+}$-cell populations, but diminishing viral pathogenesis, was another focus of the CMV vaccine vector design (38-42). 
Interestingly, an MCMV vector encoding a CD8+ T-cell epitope derived from the IAV HA gene (43)

99 induced protective $\mathrm{CD}^{+} \mathrm{T}$-cell responses against IAV, but only when administered intranasally 100 and eliciting responses from mucosa resident $C D 8^{+} \mathrm{T}$ cells (37), which was similar to effects 101 observed upon immunization with an MCMV vector targeting an epitope of the respiratory 102 syncytial virus (44).

103 In this study, we constructed recombinant MCMVs expressing either the full-length IAV HA protein $104\left(\mathrm{MCMV}^{\mathrm{HA}}\right)$, or SARS-CoV-2 S protein $\left(\mathrm{MCMV}^{\mathrm{S}}\right)$. We used these vectors to immunize mice and 105 analyzed their immunoprotective effects. We also compared the MCMV ${ }^{\mathrm{HA}}$ immune protection to 106 those induced by a vector expressing the optimally positioned immunodominant epitope from the 107 same virus. We show that immunization with MCMVs expressing a full-length-protein efficiently 108 induced neutralizing antibodies and protected the animals against viral challenge despite poor $109 \mathrm{CD}^{+} \mathrm{T}$ cell-responses. Experiments in B-cell deficient JHT mice demonstrated that the immune 110 protection conferred by a single-dose administration of the MCMV vector was not only robust and 111 lasting, but also antibody-dependent. This advances the design of MCMV-based vaccines. 


\section{Materials and Methods}

\section{Ethics statement}

$115 \mathrm{BALB} / \mathrm{cJRj}$ and C57BL/6JRj mice were purchased from commercial vendors (Janvier, Le Genest 116 Saint Isle, France). B6.129P2-Igh-Jimign/J (JHT) mice were bred in the animal facility of Helmholtz 117 Center for Infection Research, Braunschweig. Animals were housed under SPF conditions at $\mathrm{HZI}$ 118 or Hebrew University in Jerusalem and handled according to the good animal practice as defined 119 by Federation of Laboratory Animal Science Associations (FELASA). Animal experiments were 120 approved by the Lower Saxony State Office of Consumer Protection and Food Safety and Hebrew

121 University Medical School Ethic committee.

\section{Cell culture and viruses}

123 Vero E6 (CRL-1586), Vero76 (ATCC CRL-1586), 293T (DSMZ ACC-635), MDCK (CCL-34) and 124 M2-10B4 cells (ATCC CRL-1972) were cultured in DMEM (Gibco, NY, USA) supplemented with $12510 \%$ fetal bovine serum (FBS), $2 \mathrm{mM} \mathrm{L}$-glutamine, $100 \mathrm{IU} / \mathrm{mL}$ penicillin and $100 \mu \mathrm{g} / \mathrm{mL}$ 126 streptomycin. C57BL/6 primary mouse embryo fibroblast (MEF) cells were prepared in-house 127 from C57BL/6JRj mice. The PR8M variant of Influenza A/PR/8/34 was obtained from the strain 128 collection at the Institute of Molecular Virology, Muenster, Germany. SARS-CoV-2 South Tyrol 129 strain (FI strain, hCoV-19/Germany/Muenster_FI1103201/2020, GISAID database ID: 130 EPI_ISL_463008) was isolated by Stephan Ludwig lab. MCMVWT refers to the BAC-derived 131 molecular clone (pSM3fr-MCK-2fl clone 3.3) (Jordan et al., 2011).

\section{Virus mutagenesis}

133 MCMV virus mutants are based on the BAC molecular clone pSM3fr-MCK-2fl clone 3.3, where 134 recombinant variants were generated by en passant mutagenesis, as described previously (45, 135 46). The construction of MCMV IVL has been described previously (37). 
MCMV variants expressing the hemagglutinin protein were constructed using either the wild-type

137 MCMV genome or the $\triangle$ m152-RAE1y MCMV genome (Slavuljica et al., 2010) to generate $138 \mathrm{MCMV}^{\mathrm{HA}}$ and Rae-1YMCMV ${ }^{\mathrm{HA}}$. $\mathrm{MCMV}^{\mathrm{HA}}$ was generated by replacing m157 ORF with an 139 expression cassette containing the human CMV major immediate-early enhancer and promotor 140 (hMIEP), the hemagglutinin ORF (Fig. S4A). The hemagglutinin ORF was amplified from pUC18 141 vector containing the hemagglutinin ORF of the PR8 strain (UniProt P03452) that was kindly 142 provided by Peter Stäheli. Recombinant MCMV expressing SARS-CoV-2 spike was generated 143 by inserting the spike ORF in place of the ie2 gene by replacing the start and stop codon of the 144 spike ORF with the start and stop codon of the ie2 ORF. The spike ORF was amplified from 145 146 MN_908947).

\section{Virus stock generation and plaque assay}

148 BAC-derived mutant MCMVs were propagated on M2-10B4 cells and purified by sucrose density 149 gradient as described previously (46). Influenza virus was generated and infectious virus 150 quantified as described previously (37). SARS-CoV-2 virus stocks were generated essentially as 151 described (47). Briefly, infected Vero E6 cells and supernatants were harvested, centrifuged to 152 remove the cell debris and concentrated by Vivaspin® 20 concentrators (Sartorius, Goettingen, 153 Germany) according to manufacturer's instructions. Infectious titer was determined by serially 154 diluting the virus stocks, followed by infection of Vero E6 monolayers in 24-well plates for an hour 155 at $37^{\circ} \mathrm{C}$. Thereupon, the inoculum was removed and the cells overlaid with $1.5 \%$ methylcellulose. 156 Cells were incubated at $37^{\circ} \mathrm{C}$ for 4 days, fixed with $6 \%$ PFA for an hour, stained with crystal violet, 157 and plaque numbers were counted under an inverted microscope. 


\section{Virus in vivo infection}

159 Female BALB/c mice aged 7-8 weeks were intraperitoneally (i.p.) immunized with $2 \times 10^{5}$ PFU of 160 recombinant MCMVs expressing antigens or with parental control virus diluted in PBS (200 $\mu$ l per 161 animal). Blood was acquired at indicated time points.

162 For B-cell depleted animal challenge experiments, 6-8 weeks old BALB/c and JHT female mice 163 were i.p. immunized with $2 \times 10^{5}$ PFU MCMV ${ }^{H A}$ or $M M^{\prime I V L}$ diluted in PBS. For influenza infection, 164 mice were first anesthetized with ketamine $(10 \mathrm{mg} / \mathrm{ml})$ and xylazine $(1 \mathrm{mg} / \mathrm{ml})$ in $0.9 \% \mathrm{NaCl}(100$ $165 \mu \mathrm{l} / 10 \mathrm{~g}$ body weight), then challenged intranasally with $1100 \mathrm{FFU}$ of PR8M influenza virus as 166 described previously (37).

167 Rae-1YMCMV ${ }^{H A}$ immunizations were performed by infecting C57BL/6 mice via f.p. route with $1682 \times 10^{5} \mathrm{PFU}$ of indicated recombinant MCMVs. 21 days post immunization mice were challenged 169 via i.n. route with either high (100 hemagglutinin units, $\mathrm{HU}$ ) or low dose (40 HU) of PR8M influenza 170 virus.

\section{Detection of anti-spike antibodies in mouse sera}

172 ELISA (Enzyme-Linked ImmunoSorbent Assay) was used to detect SARS-CoV-2 Spike-specific 173 IgGs presence in mouse sera. Antigens were produced in insect cells using a baculovirus-free system according to previous publications (48) and immobilized (30ng/well) in carbonate buffer

$175\left(50 \mathrm{mM} \mathrm{NaHCO} 3 / \mathrm{Na}_{2} \mathrm{CO}_{3}, \mathrm{pH} 9.6\right)$ at $4^{\circ} \mathrm{C}$ overnight. ELISA plates were blocked with $2 \%(\mathrm{w} / \mathrm{v})$ 176 milk powder and $0.05 \%$ Tween-20 in PBS (2\% MBPST) and washed with $0.05 \%$ Tween20 in $\mathrm{H}_{2} \mathrm{O}$.

177 To determine IgG titers, mouse sera were diluted 1:100 in 2\% MBPST and further titrated in an 178 ELISA assay using S1-S2-His and RBD-SD1-HIS as antigens or BSA as control for unspecific 179 binding. In addition, all sera were also tested at the highest concentration for unspecific cross180 reactivity on Expi293F cell lysate and lysozyme (both $30 \mathrm{ng} /$ well). After $1 \mathrm{~h}$ incubation at $37^{\circ} \mathrm{C}$ and 181 washing as reported above, mouse lgGs were detected using goat anti-mouse serum conjugated 
with horseradish peroxidase (HRP) (Sigma-Aldrich, Munich, Germany). Bound antibodies were visualized with tetramethylbenzidine (TMB) substrate. After stopping the reaction by addition of $5 \% \mathrm{H}_{2} \mathrm{SO}_{4}$, absorbance at $450 \mathrm{~nm}$ with a subtracted $620 \mathrm{~nm}$ reference was measured in an ELISA plate reader (Epoch, BioTek, Winooski, VT, USA). Titration assays were performed using 384 well microtiter plates (Greiner, Kremsmuenster, Austria) using Precision XS microplate sample processor (BioTek, Winooski, VT, USA), EL406 washer dispenser (BioTek, Winooski, VT, USA) and BioStack Microplate stacker (BioTek, Winooski, VT, USA). EC 50 were calculated with GraphPad Prism Version 6.1, fitting to a four-parameter logistic curve.

\section{Antibody avidity assay}

Antibody avidity determination was performed essentially as reported previously (49). ELISA 96well plates (Costar, Corning, NY, USA) were used to immobilize SARS-CoV-2 S1-S2-HIS ectodomain at $100 \mathrm{ng} /$ well in carbonate buffer ( $\left.50 \mathrm{mM} \mathrm{NaHCO} / \mathrm{Na}_{2} \mathrm{CO}_{3}, \mathrm{pH} 9.6\right)$ at $4^{\circ} \mathrm{C}$ overnight. After blocking in $2 \%$ MPBST, mouse sera were pooled to a final dilution of 1:300 in $2 \%$ MPBST and incubated $1 \mathrm{~h}$ at $37^{\circ} \mathrm{C}$ on immobilized S1-S2-HIS. After washing with PBS with 0,05\% Tween 20, v/v (PBST), plates were incubated with indicated dilutions of NaSCN for $15 \mathrm{~min}$ at room temperature, $350 \mathrm{rpm}$, followed by immediate washing with PBST. IgGs were detected using antimouse serum conjugated with HRP (A0168, Sigma-Aldrich, Munich, Germany) and absorbance was measured as described above. Values obtained in absence of NaSCN were normalized to represent $100 \%$ of IgG binding. Hence, the avidity of Spike-specific antibodies was calculated from the ratio of the absorbance of antibodies bound after treatment with graded concentrations of $\mathrm{NaSCN}$ relative to the signal in $\mathrm{NaSCN}$ absence. One way ANOVA to compare multiple groups was performed with Dunnett's correction for multiple analyses.

\section{Hemagglutination Inhibition Assay (HAl)}


Serum samples were derived from mice at day 28 post $\mathrm{MCMV}^{\mathrm{HA}}$ or MCMVIVL immunization (dpi), or at day 5 after IAV challenge. Sera were tested for HA-specific antibody titers by standard methods using a $0.7 \% \mathrm{v} / \mathrm{v}$ turkey erythrocyte suspension, as described previously (50). In brief, to remove non-specific inhibitors, sera were treated 1:5 and 1:2, respectively with receptordestroying enzyme (Seiken, Tokyo, Japan) overnight, before heat-inactivation $\left(56^{\circ} \mathrm{C}, 30 \mathrm{~min}\right)$. Sera samples were added to 96 -well v-bottomed microtiter plates at a starting dilution of 1:10. The serum $\mathrm{HI}$ titers are expressed as the reciprocal of the highest dilution at which $50 \%$ hemagglutination was inhibited. A surrogate correlate of protection was extrapolated from seasonal vaccination in humans, using a titer above $\geq 40$ to indicate sero-protection and a serum titer less than 5 as negative result.

\section{In vitro serum neutralization titer (SNT) assay}

Serum was heat-inactivated for $30 \mathrm{~min}$ at $56^{\circ} \mathrm{C}$, serially diluted at $1: 2$ steps and incubated with 100PFU/100 $\mu$ l of SARS-CoV-2 for an hour at RT. For IgM depletion, heat-inactivated sera were incubated with 2-ME for an hour at RT prior to mixing with the virus. $2 \times 10^{4}$ Vero-E6 cells seeded in 96-well plates were inoculated with serum and virus and incubated at $37^{\circ} \mathrm{C}$ and $5 \% \mathrm{CO}_{2}$ for $1 \mathrm{~h}$. After removing the inoculum, cells were overlaid with $1.5 \%$ methylcellulose. Infected cells were incubated at $37^{\circ} \mathrm{C}$ and $5 \% \mathrm{CO}_{2}$ for 3 days, prior to crystal violet staining and plaque counting.

\section{Pseudovirus neutralization assay}

We used vesicular stomatitis virus (VSV) pseudotyped with SARS-CoV-2 S according to a published protocol (51) and described in detail previously (52). In brief, 293T cells were transfected with expression plasmids for SARS-CoV-2 S proteins of either Wuhan/Hu-1/2019 (lineage B, with D614G mutation inserted, codon-optimized), hCoV-19/England/MILK9E05B3/2020 (lineage B.1.1.7, codon-optimized), or hCoV-19/South Africa/NHLS-UCT-GS1067/2020 (lineage B.1.351, codon-optimized) or empty expression vector (negative control, used 
229 to generate bald control particles) by the calcium-phosphate method. At $24 \mathrm{~h}$ posttransfection, the 230 transfection medium was removed and cells were inoculated with a replication-deficient VSV 231 vector lacking the genetic information for the VSV glycoprotein (VSV-G) and instead coding for 232 an enhanced green fluorescent protein and firefly luciferase from independent transcription units, $233 V^{*} V^{*} \Delta G-F L u c$ (kindly provided by Gert Zimmer, Institute of Virology and Immunology, 234 Mittelhäusern, Switzerland) (53). Following $1 \mathrm{~h}$ of incubation at $37^{\circ} \mathrm{C}$ and $5 \% \mathrm{CO}_{2}$, the inoculum 235 was removed and cells were washed with PBS, before culture medium containing anti-VSV-G 236 antibody (culture supernatant from I1-hybridoma cells; ATCC CRL-2700) was added and cells 237 were further incubated. The pseudotype particles were harvested at 16-18h post-inoculation. For 238 this, the culture medium was collected, centrifuged $(2,000 \times \mathrm{g}, 10 \mathrm{~min}, \mathrm{RT})$ to pellet cellular debris, 239 and the clarified supernatant was transferred into fresh tubes and stored at $-80^{\circ} \mathrm{C}$ until further 240 use. Each batch of pseudotypes was pre-tested for comparable transduction efficiencies by the 241 respective $\mathrm{S}$ proteins and absence of transduction by control particles lacking any surface 242 glycoprotein before being used in neutralization experiments.

243 For neutralization experiments, equal volumes of pseudotype particles and serum dilution or 244 medium (control) were mixed and incubated for 30 min at $37^{\circ} \mathrm{C}$ before being inoculated onto 245 Vero76 cells grown in 96-well plates (100 $\mu \mathrm{l} /$ well, samples were analyzed in technical triplicates). 246 Transduction efficiency, was analyzed at $16 \mathrm{~h}$ post-transduction. For this, the medium was 247 aspirated and cells were lysed by incubation with Cell Culture Lysis Reagent (Promega, Madison, 248 WI, USA) for $30 \mathrm{~min}$. Lysates were transferred in white 96 -well plates and luciferase activity was 249 measured by adding a commercial substrate (Beetle Juice, PJK, Kleinblittersdorf, Germany) and 250 recording the luminescence signals (given as counts per second) with a Hidex Sense plate 251 luminometer (Hidex, Okegawa, Victoria). 


\section{Influenza virus ex vivo titration}

253 Mice were sacrificed by $\mathrm{CO}_{2}$ inhalation. Entire lungs were dissected and mechanically

254 homogenized using a tissue homogenizer. Homogenates were spun down and supernatants were 255 stored at $-70^{\circ} \mathrm{C}$. Lung virus titers were determined by using the focus-forming assay (FFA), as 256 described before (54) with minor modifications. Supernatants of lung tissue homogenates were 257 serially diluted in DMEM, supplemented with $0.1 \%$ BSA and N-acetylated trypsin (NAT; $2.5 \mu \mathrm{g} / \mathrm{ml}$ ), 258 and added to the MDCK cell monolayers. After $1 \mathrm{~h}$ incubation, cells were overlaid with DMEM 259 supplemented with $1 \%$ Avicel, $0.1 \%$ BSA and NAT $(2.5 \mu \mathrm{g} / \mathrm{ml})$. After $24 \mathrm{~h}$, cells were fixed with $2604 \%$ PFA and incubated with quenching solution (0.5\% Triton X-100, $20 \mathrm{mM}$ Glycin in PBS). Cells 261 were then treated with blocking buffer (1\% BSA, 0.5\% Tween-20 in PBS). Focus forming spots 262 were identified using primary polyclonal goat anti-H1N1 IgG (Virostat, Westbrook, ME, USA), 263 secondary polyclonal rabbit anti-goat $\operatorname{lgG}$ conjugated with horseradish peroxidase and 264 TrueBlue $^{\mathrm{TM}}$ peroxidase substrate (KPL TrueBlue ${ }^{\mathrm{TM}}$, SeraCare Life Science Inc., Milford, MA, 265 USA). Viral titers were calculated as focus forming units (FFU) per $\mathrm{ml}$ of lung tissue homogenate.

\section{Quantification of T cell responses}

267 Peripheral blood was harvested and lymphocytes were isolated as described previously (Oduro 268 et al., 2016). PBMCs were stimulated with peptide at $1 \mu \mathrm{g} / \mathrm{ml}$ in $85 \mu \mathrm{l}$ RPMl 1640 for $1 \mathrm{~h}$ at $37^{\circ} \mathrm{C}$, 269 upon which $15 \mu \mathrm{l}$ brefeldin $\mathrm{A}(10 \mu \mathrm{g} / \mathrm{ml})$ was added and cells incubated for additional $5 \mathrm{~h}$ at $37^{\circ} \mathrm{C}$. 270 Lymphocytes were stained with fluorescent-labeled antibodies against CD3 (17A2, eBiosciences, 271 San Diego, CA, USA), CD4 (GK1.5, BioLegend, San Diego, CA, USA), CD8a (53-6.7, BioLegend, 272 San Diego, CA, USA), CD44 (IM7, BioLegend, San Diego, CA, USA) and CD11a (2D7,

273 Bioscience, San Diego, CA, USA). Subsequently, cell were fixed and permeabilized (IC fixation 274 buffer and permeabilization buffer, eBioscience, San Diego, CA, USA) and intracellular cytokines 275 were labelled with anti-IFNy (XMG1.2, BioLegend, San Diego, CA, USA) and anti-TNFa (MP6- 
276 XT22, BioLegend, San Diego, CA, USA) antibodies. The labeled cells were analyzed by flow

277 cytometry and antigen specific CD8+ T cell response was measured.

\section{Western blot}

279 Sucrose-cushion purified viruses were diluted with PBS and then used to measure protein amount 280 by BCA assay according to the manufacturer's protocol (Pierce ${ }^{\mathrm{TM}}$ Micro $\mathrm{BCA}^{\mathrm{TM}}$ Protein-Assay, 281 ThermoFisher, Waltham, MA, USA). Samples were treated with 2-mercaptoethanol and sample 282 reducing buffer, and then incubated at $95^{\circ} \mathrm{C}$ for $5 \mathrm{~min}$. Proteins were separated by SDS-PAGE, 283 transferred on an Immobilon-P PVDF membrane (MilliporeSigma, Munich, Germany) and blocked 284 with $5 \%$ milk in TBS-T. Primary antibodies were allowed to bind overnight at $4^{\circ} \mathrm{C}$, followed by a 285 wash in TBS-T and secondary antibody binding for an hour at RT. Upon another wash, the images 286 were acquired by Chemostar PC ECL \& Fluorescence Imager (Intas Science, Goettingen, 287 Germany). Anti-SARS-CoV-2 spike (1A9, GeneTex, Irvine, CA, USA), anti-HA (kindly provided by 288 W. Gerhard from Philadeplhia), anti-MCK-2 (kindly provided from Stipan Jonjic) and IE1 (IE 1.01, 289 CapRi, Rijeka, Croatia) were used for primary antibodies. Anti-rabbit IgG (ab205718), anti-mouse 290 IgG (ab97046) were used for secondary antibodies.

\section{Statistics}

292 Comparisons between two groups were performed using the Mann-Whitney U test (two-tailed). 293 One way ANOVA with Dunnett's correction was performed for multiple group analysis. Two-way 294 ANOVA analysis was used to compare multiple groups at multiple time points. Statistical analysis was calculated by GraphPad Prism 6-9. 


\section{Results}

297 Generation of recombinant MCMVs expressing the influenza hemagglutinin or the SARS

\section{Cov-2 S protein}

299

We recently showed that $M C M V^{I V L}$, a recombinant $M C M V$ vaccine expressing the ${ }_{533}$ IYSTVASSL ${ }_{541}$ epitope (IVL) from the IAV HA protein, protects against influenza challenge when administered intranasally by inducing mucosal resident CD8 ${ }^{+} \mathrm{T}$ cells $(37)$. We considered the possibility that a recombinant MCMV expressing the full-length HA may provide a similar or better immune protection. Therefore, we generated a recombinant MCMV expressing the fulllength HA using a BAC containing the MCMV genome (pSM3fr-MCK-2fl), where the viral m157 gene, which is dispensable for virus in vivo replication (55), was replaced with the whole HA gene

(Fig. 1A). Since MCMV vectors expressing ligands for the activating NKG2D receptor show

307 improved immune protection over parental viruses (39), we generated another recombinant

308 MCMV that expressed the Rae-1y ligand instead of the MCMV gene m152 in addition to the IAV $309 \mathrm{HA}$ gene in the m157 locus and named it Rae-1yMCMV ${ }^{H A}$ (Fig. S1A).

310 We also generated a recombinant MCMV expressing the gene for the S protein. We replaced the 311 immediate early 2 (ie2) gene of MCMV with the S gene of SARS-CoV-2, because ie2 is 312 dispensable for viral replication and dissemination (56). Thus, using BAC-based recombination 313 we generated a new recombinant virus called MCMVS (Fig. 1B). The HA and S proteins were 314 detected by Western blot in the purified virus stocks of MCMVHA or MCMVS, respectively (Fig. 1C 315 and 1D) and grew with similar kinetics as the wild-type virus (not shown).

316 Immunization with MCMV expressing the full-length $\mathbf{S}$ protein induces neutralizing 317 antibody responses.

318 BALB/c mice were i.p. immunized with MCMVs, MCMVWT, or PBS (mock). Blood was collected at 319 7, 14, 28 and 56 dpi and sera were tested for antigen specific responses against the entire $S$ 
protein or the receptor binding domain (RBD) by ELISA. We observed notable serum responses

321 in mice immunized with $\mathrm{MCMV}^{s}$ at all indicated time points, peaking by $28 \mathrm{dpi}$ (Fig. 2A).

322 We next tested the serum neutralization capacity. We used recombinant vesicular stomatitis virus

323 (VSV) expressing the S gene of SARS CoV-2 isolates hCoV-19/Wuhan/WH01/2019 (B lineage,

324

325

326

327

328

329

330

331

332

333

334

335

336

with introduced D614G mutation) hCoV-19/England/MILK-9E05B3/2020 (B.1.1.7 lineage) or hCoV-19/South Africa/NHLS-UCT-GS-1067/2020 (B.1.351 lineage). Following SARS-CoV-2 S protein-driven cell entry, the pseudoviruses express firefly luciferase, which was used as an indicator of infectivity and to analyze the neutralization capacity of the mouse sera. We tested five mouse sera collected 56 days post MCMVs inoculation and observed an average pseudovirus neutralization titer $\left(\mathrm{pVNT}_{50}\right)$ of $1: 900$ for pseudotypes bearing either SARS-CoV-2 S WH01+D614G or B.1.1.7, and a slightly reduced, but still robust $\mathrm{pVNT}_{50}$ of 1:450 for particles harboring SARS-CoV-2 S B.1.351 (Fig. 2B). Therefore, we concluded that the MCMV vector induces robust neutralization titers against multiple clinically-relevant SARS-CoV-2 variants. We next tested the dynamics of serum neutralization capacity against a bona fide SARS-CoV-2 isolate. Sera were incubated with SARS-CoV-2 and serum titers resulting in a $50 \%$ neutralization of virus $\left(\mathrm{VNT}_{50}\right)$ were determined. A part of each serum sample was pre-incubated with 2mercaptoethanol (2-ME), which specifically destroys the neutralizing activity of $\operatorname{lgM}(57)$. Therefore, these samples essentially showed the neutralization capacity of the $\lg$ antibody class, which is dominant in the serum. We observed that the neutralizing antibody titers against SARS-CoV-2 increased from an average $\mathrm{VNT}_{50}$ titer of 1:84 at 7 dpi to 1:476 at 56 dpi (Fig. 2C and Table 1) for the whole serum fraction and from values below the limit of detection at $7 \mathrm{dpi}$ to 1:407 at 56 dpi for the $\lg$ G serum fraction. While 3 out of 29 sera ( 2 sera at 14 dpi and 1 at 56 dpi) did not show any neutralizing capacity (we assume that these mice were not properly immunized due to technical reasons), the vast majority of $\mathrm{MCMV}^{\mathrm{S}}$ treated mice showed a clear immunization effect (Fig. 2C and S2). On the other hand, MCMVWT and mock-immunized mice 
showed no specific immune responses against SARS-CoV-2 at any time, suggesting that the protection was specifically induced by the expression of the S protein from the MCMV vector (Fig.

347 S3).

Interestingly, neutralization titers in 2-ME treated groups were essentially comparable to those from untreated groups by dpi 28 (Fig. 2C and Table 1), arguing that the fraction of class-switched antibodies increased significantly at later time points. Furthermore, the antibody titer peaked at $28 \mathrm{dpi}$, while the neutralization capacity kept expanding until the last measured time point at 56 dpi. Taken together, these observations implied a robust germinal center reaction leading to somatic hypermutations and affinity maturation. We measured therefore the binding avidity of serum antibodies over time by sodium thiocyanate (NaSCN) inhibition $(49,58)$. Sera from MCMVs immunized mice were treated by graded amounts of NaSCN and residual binding to $S$ was determined by ELISA as indicator of avidity. Binding avidity increased consistently and continuously from 7 to $56 \mathrm{dpi}$ (Fig. 2D and 2E). Therefore, the increase in neutralization capacity over time (Fig. 2C) was matched by an increase in binding avidity (Fig. 2D), rather than by an increase in the amount of antibodies (Fig. 2A).

Immunization with MCMV expressing the full-length HA protein induces neutralizing antibody responses.

To test if antibody responses can be elicited against another respiratory virus, we tested the hemagglutination inhibition ( $\mathrm{HAI})$ serum titers at 28 days post immunization with MCMV ${ }^{\mathrm{HA}}$. As control, we used the MCMVIVL, an MCMV expressing solely an immunodominant MHC-I restricted octameric epitope from IAV HA (37). HA-specific antibodies were detected in MCMV ${ }^{H A}$ immunized mice, but not in those vaccinated with $\mathrm{MCMV}^{\mathrm{IVL}}$ (Fig. 2F). Therefore, the MCMV vaccine vector expressing the full-length HA induced humoral responses that recognized HA and impaired its binding, and this was not due to cross reactivity to MCMV antigens, as seen in the MCMVIVL control group. 
371 C57BL/6 mice were i.p. immunized with MCMVHA. Control groups were not infected, or infected 372 with the parental virus $\mathrm{MCMV}^{\mathrm{Am} 157}$ which lacks the $m 157$ gene, but does not express the HA gene.

373 Mice were challenged with lethal IAV doses at 21 days post immunization and weight loss and 374 mortality were followed. PBS immunized mice showed severe body weight loss and mortality, 375 whereas MCMV ${ }^{H A}$ immunized mice showed no weight loss and no mortality (Fig. 3A and 3B). We 376 compared the effects of immunization with Rae-1YMCMVHA to the parental MCMVHA and $377 M^{M C M V}{ }^{\Delta m 157}$ viruses by measuring weight loss kinetics for 5 days upon IAV challenge. We also 378 measured flu virus titers in the lungs of challenged mice at 5 days post IAV challenge. While weight loss was averted in both groups immunized with MCMVs expressing the HA gene, and flu titers were reduced in the same groups relative to control mice that were immunized with $\mathrm{MCMV}^{\mathrm{Am} 157}$ or not immunized at all (Fig. S1B and S1C), Rae-1YMCMVHA immunization did not reduce titers more efficiently than $\mathrm{MCMV}^{\mathrm{HA}}$. Hence, the MCMVs encoding HA provided immune protection against IAV challenge, irrespective of RAE1Y expression.

Since $\mathrm{MCMV}^{\mathrm{HA}}$ provided immune protection even when applied i.p., whereas MCMV ${ }^{\mathrm{IVL}}$ was protective only when applied i.n. (37), and since HAI titers were induced exclusively by MCMVHA

(Fig. 2F), we considered the possibility that $\mathrm{MCMV}^{\mathrm{HA}}$ induces stronger adaptive immune responses than MCMVIVL. Therefore, we compared IVL-specific $\mathrm{K}^{\mathrm{d}}$-restricted $\mathrm{CD}^{+} \mathrm{T}^{+}$-cell responses upon $\mathrm{MCMV}^{\mathrm{IVL}}$ or $\mathrm{MCMV}^{\mathrm{HA}}$ infection in BALB/c mice. We monitored the frequency of

$389 \mathrm{IFNy}{ }^{+} \mathrm{CD}^{+} \mathrm{T}$ cells until $115 \mathrm{dpi}$ and observed that IFNy+ $\mathrm{CD}^{+}$T-cell counts robustly increase in 390 MCMV ${ }^{\mathrm{IVL}}$ immunized mice, but barely in $\mathrm{MCMV}^{\mathrm{HA}}$ immunized groups, both in relative and absolute 391 terms (Fig. 3C). Similar responses were observed at 7 days post IAV challenge, where mice 392 primed with MCMV ${ }^{\mathrm{IVL}}$ showed substantially stronger cytokine responses in the $\mathrm{CD}^{+}{ }^{+}$compartment upon in vitro restimulation with the IVL peptide (Fig. 3D). Hence, our data indicated that superior protection provided by $\mathrm{MCMV}^{\mathrm{HA}}$ may not be due to stronger cellular immunity. 
To directly compare the protective capacity of MCMV IVL and MCMV ${ }^{H A}$, we challenged the mice with IAV at times of virus latency (>3 months post immunization) and measured the IAV titer in

397 the lungs of immunized mice at 5 days post challenge. No infectious IAV could be detected in $398 \mathrm{MCMV}^{\mathrm{HA}}$ immunized mice, whereas all MCMV ${ }^{\mathrm{IVL}}$ immunized mice showed clearly detectable virus 399 titers (Fig. 3E). We also monitored body weight upon IAV challenge and observed a significant 400 drop in mice immunized with MCMV $^{\mathrm{IVL}}$ but not in those immunized with MCMVHA (Fig. 3F). 401 Intriguingly, only MCMV ${ }^{H A}$ immunized mice showed robust HAI serum titers at 5 days post IAV 402 challenge (Fig. 3G). Therefore, our results suggested that the virus expressing the full-length HA 403 gene provides better immune protection, likely due to humoral immune responses.

MCMV full-length-protein vector gives protection against viral challenge through humoral 405 response.

406 While our results showed that MCMVs expressing viral glycoproteins induce neutralizing 407 immunity, it was not formally proven that the humoral immunity was essential for immune 408 protection upon challenge. To test this directly, we immunized B-cell deficient JHT mice with $409 \mathrm{MCMV}^{\mathrm{HA}}$ and challenged them with IAV at 120 days post immunization (Fig. 4A). As expected, 410 HA-specific antibodies were observed only in the immunized BALB/c mice, while no functional 411 HA-specific antibodies could be detected in JHT mice (Fig. 4B). Similarly, viral titers were detected 412 only in the lungs of vaccinated JHT mice, but were absent from BALB/c controls (Fig. 4C). 413 Moreover, JHT mice suffered a significant weight loss upon IAV challenge whereas WT littermates 414 did not (Fig. 4D). Taken together, these results indicated a critical role of antibodies in controlling 415 IAV. Our data demonstrate that MCMVs expressing a full-length-protein provide immune 416 protection against respiratory viral challenge and this protection depends on the humoral 417 response of neutralizing antibodies. 


\section{Discussion}

419 CMV has aroused great interest as a vaccine vector in recent years due to its strong 420 immunogenicity and ability to establish life-long inflationary CD8 ${ }^{+} T$ cell-response (59). Many 421 studies have demonstrated that exogenous antigens fused to the CMV genome provide protection

422 against corresponding pathogens, but almost all of the previous publications handled T cell-based

423 immune protection $(17,18,20,21,28,37)$ and barely covered $B$ cell-based humoral responses,

424 which prevent viral spread via extracellular fluids (60). One detailed study has shown that MCMVs

425 induce protective humoral immune responses against a murine retrovirus (61), but it remained

426 unclear if this principle applies to clinically relevant pathogens. Humoral immunity against the

427 Ebola glycoprotein protein was observed upon immunization of rhesus monkeys with an RhCMV

428 vector by ELISA, but the sera showed no virus neutralization capacity (21). In this study, we

429 constructed MCMV-based vaccine vectors against two pandemic viruses, IAV and SARS-CoV-2,

430 and demonstrated that neutralizing humoral immune responses against both are induced by

431 recombinant MCMV vaccination, and that immune protection is abrogated in B-cell deficient mice.

432 Humoral immunity elicited by MCMV ${ }^{H A}$ provided better protection against IAV challenge than the

433 robust cellular immunity elicited by MCMVIVL. Furthermore, the insertion of Rae-1y was previously

434 shown to promote memory CD8 ${ }^{+}$T-cell responses, thus improving protection by CMV vectors (39,

435 62, 63), but Rae-1y did not improve MCMVHA protection against IAV challenge in this system,

436 arguing against a role of $\mathrm{T}$-cells in $\mathrm{MCMV}^{\mathrm{HA}}$ mediated protection. Taken together, our evidence

437 strongly argues that humoral immunity was both sufficient and necessary to provide immune 438 protection against respiratory virus challenge.

439 Previous results showed, however, that MCMV vectors expressing a single MHC-I restricted 440 peptide are sufficient to provide protection against viral challenge $(20,28,33,35)$. Even more 441 surprisingly, others and we have shown that MCMVs expressing a single immunodominant 442 peptide provide better protection than those carrying the full-length protein $(34,64)$. Here we 
observed the exactly opposite phenotype, where the full length protein provided better protection.

444 However, systemic inflationary T-cell responses do not protect against influenza or respiratory 445 syncytial virus $(37,44)$, and i.p. immunization, as performed in this study, does not elicit the 446 protective lung mucosal $\mathrm{CD}^{+} \mathrm{T}$-cell responses. Therefore, our data may indicate that respiratory 447 viral infections may be controlled better by systemic humoral immunity than by systemic cellular 448 immunity.

449 Our study did not address the potential of CMV vectors to elicit mucosal humoral immunity and if 450 it would provide better protection against IAV or SARS-CoV-2 infection. This question is intriguing, 451 but goes beyond the scope of the present manuscript. Hence, it needs to be addressed in future 452 studies, whether intranasal administration of MCMV vectors induces mucosal $(\lg A)$ antibody 453 responses and if this would further improve immune protection.

454 Immediate early genes, especially ie1 and ie2 of MCMV, are sporadically expressed during the 455 latency, enhancing the formation of memory inflation (65). A similar induction of humoral immunity 456 against CMV antigens was documented in a previous study (49). We used ie promoters to express 457 the S or HA proteins and observed an ongoing increase in the neutralizing capacity of sera up to 4588 weeks post infection and robust immune protection at three months post immunization. One 459 explanation for these phenomena may be the continuous restimulation of antigen-specific B cells 460 by sparse antigen expression during latency, boosting B-cell immunity over time. While this 461 hypothesis needs to be experimentally validated in future studies, our data demonstrate that the 462 level of neutralizing antibodies increased over time, that the level of class-switched isotypes 463 gradually increased and dominated at later time points after vaccination and that this was 464 concomitant with an increase in avidity. All of these findings implicate somatic hypermutation 465 processes upon germinal center reactions elicited by the MCMV vector immunization.

466 In summary, our data argue that a single injection of an MCMV vector may be sufficient to induce 467 protective B-cell memory responses against respiratory viral pathogens, which is an improvement 
over most among the currently available vaccine formulations against COVID-19. This also

469 argues that CMV vectors might be used as vaccine tools against other pathogens that may

470 emerge in the future. In light of observations that replication-deficient CMV vectors provide long-

471 term immune protection $(40,42,66)$, it is possible to envisage vaccine formulations that combine

472 safety and long-term humoral immune protection. This study provides a crucial contribution in that 473 direction.

\section{Acknowledgments}

475 We thank Inge Hollatz-Rangosch, Bettina Fürholzner, Martina Grashoff and Tatjana Hirsch for 476 expert technical assistance and Susanne Talay and Andrea Kröger for advice and support. We 477 thank Christine Goffinet for providing us the Vero-E6 cell line. This research was supported by 478 the grant 14-76103-84 from the Ministry of Science and Culture of Lower Saxony to LCS, by the 479 Helmholtz Association Eu Partnering grant MCMVaccine (PEI-008) to LCS and SJ, and by the 480 European Union's Horizon 2020 research and innovation programme under grant agreement No 481101003650 to $\mathrm{MH}$.

\section{Declaration of Interests}

484 The authors declare no competing interest.

\section{Reference}

487 1. Chen JR, Ma C, Wong $\mathrm{CH}$. Vaccine design of hemagglutinin glycoprotein against influenza. Trends 488 Biotechnol. 2011;29(9):426-34.

4892 2. Sriwilaijaroen N, Suzuki Y. Molecular basis of the structure and function of H1 hemagglutinin of 490 influenza virus. Proc Jpn Acad Ser B Phys Biol Sci. 2012;88(6):226-49. 
491 3. Cheng YW, Chao TL, Li CL, Chiu MF, Kao HC, Wang SH, et al. Furin Inhibitors Block SARS-CoV-2 492 Spike Protein Cleavage to Suppress Virus Production and Cytopathic Effects. Cell Rep. 2020:108254.

493 4. Hoffmann M, Kleine-Weber H, Pohlmann S. A Multibasic Cleavage Site in the Spike Protein of 494 SARS-CoV-2 Is Essential for Infection of Human Lung Cells. Mol Cell. 2020;78(4):779-84 e5.

495 5. Zhao P, Praissman JL, Grant OC, Cai Y, Xiao T, Rosenbalm KE, et al. Virus-Receptor Interactions of 496 Glycosylated SARS-CoV-2 Spike and Human ACE2 Receptor. Cell Host Microbe. 2020;28(4):586-601 e6.

497 6. Hoffmann M, Kleine-Weber H, Schroeder S, Kruger N, Herrler T, Erichsen S, et al. SARS-CoV-2 Cell 498 Entry Depends on ACE2 and TMPRSS2 and Is Blocked by a Clinically Proven Protease Inhibitor. Cell. $499 \quad$ 2020;181(2):271-80 e8.

$500 \quad 7 . \quad$ WHO. Draft landscape of COVID-19 candidate vaccines. World Health Organization2020.

501 8. Krammer F. SARS-CoV-2 vaccines in development. Nature. 2020.

502 9. Sahin U, Muik A, Derhovanessian E, Vogler I, Kranz LM, Vormehr M, et al. COVID-19 vaccine 503 BNT162b1 elicits human antibody and T(H)1 T cell responses. Nature. 2020;586(7830):594-9.

504 10. Mahase E. Covid-19: UK approves Pfizer and BioNTech vaccine with rollout due to start next week. 505 Bmj. 2020;371:m4714.

506 11. WHO. WHO regional office for Europe. Seasonal influenza2021.

507 12. CDC. CDC seasonal Flu Vaccine Effectiveness studies. Centers for Disease Control and 508 Prevention2021.

509 13. Dawood FS, Chung JR, Kim SS, Zimmerman RK, Nowalk MP, Jackson ML, et al. Interim Estimates 510 of 2019-20 Seasonal Influenza Vaccine Effectiveness - United States, February 2020. MMWR Morb Mortal 511 Wkly Rep. 2020;69(7):177-82.

512 14. Coffman RL, Sher A, Seder RA. Vaccine adjuvants: putting innate immunity to work. Immunity. $513 \quad 2010 ; 33(4): 492-503$. 
514 15. Ura T, Okuda K, Shimada M. Developments in Viral Vector-Based Vaccines. Vaccines (Basel). $515 \quad 2014 ; 2(3): 624-41$.

516 16. Lauer KB, Borrow R, Blanchard TJ. Multivalent and Multipathogen Viral Vector Vaccines. Clinical 517 and vaccine immunology : CVI. 2017;24(1).

518 17. Lillie PJ, Berthoud TK, Powell TJ, Lambe T, Mullarkey C, Spencer AJ, et al. Preliminary assessment 519 of the efficacy of a T-cell-based influenza vaccine, MVA-NP+M1, in humans. Clinical infectious diseases : 520 an official publication of the Infectious Diseases Society of America. 2012;55(1):19-25.

521 18. Hansen SG, Ford JC, Lewis MS, Ventura AB, Hughes CM, Coyne-Johnson L, et al. Profound early 522 control of highly pathogenic SIV by an effector memory T-cell vaccine. Nature. 2011;473(7348):523-7.

523 19. Price GE, Soboleski MR, Lo CY, Misplon JA, Quirion MR, Houser KV, et al. Single-dose mucosal 524 immunization with a candidate universal influenza vaccine provides rapid protection from virulent H5N1, 525 H3N2 and H1N1 viruses. PloS one. 2010;5(10):e13162.

526 20. Hansen SG, Vieville C, Whizin N, Coyne-Johnson L, Siess DC, Drummond DD, et al. Effector memory 527 T cell responses are associated with protection of rhesus monkeys from mucosal simian immunodeficiency 528 virus challenge. Nat Med. 2009;15(3):293-9.

529 21. Marzi A, Murphy AA, Feldmann F, Parkins CJ, Haddock E, Hanley PW, et al. Cytomegalovirus-based 530 vaccine expressing Ebola virus glycoprotein protects nonhuman primates from Ebola virus infection. 531 Scientific reports. 2016;6:21674.

532 22. Alharbi NK, Padron-Regalado E, Thompson CP, Kupke A, Wells D, Sloan MA, et al. ChAdOx1 and 533 MVA based vaccine candidates against MERS-CoV elicit neutralising antibodies and cellular immune 534 responses in mice. Vaccine. 2017;35(30):3780-8.

535 23. Koch T, Dahlke C, Fathi A, Kupke A, Krahling V, Okba NMA, et al. Safety and immunogenicity of a 536 modified vaccinia virus Ankara vector vaccine candidate for Middle East respiratory syndrome: an open537 label, phase 1 trial. Lancet Infect Dis. 2020;20(7):827-38. 
538 24. Volz A, Kupke A, Song F, Jany S, Fux R, Shams-Eldin H, et al. Protective Efficacy of Recombinant

539 Modified Vaccinia Virus Ankara Delivering Middle East Respiratory Syndrome Coronavirus Spike

$540 \quad$ Glycoprotein. J Virol. 2015;89(16):8651-6.

$54125 . \quad \mathrm{Kim} \mathrm{MH}$, Kim HJ, Chang J. Superior immune responses induced by intranasal immunization with

542 recombinant adenovirus-based vaccine expressing full-length Spike protein of Middle East respiratory 543 syndrome coronavirus. PloS one. 2019;14(7):e0220196.

544 26. Karrer U, Sierro S, Wagner M, Oxenius A, Hengel H, Koszinowski UH, et al. Memory inflation:

545 continuous accumulation of antiviral CD8+ T cells over time. Journal of immunology. 2003;170(4):2022-9.

546 27. Munks MW, Cho KS, Pinto AK, Sierro S, Klenerman P, Hill AB. Four Distinct Patterns of Memory

547 CD8 T Cell Responses to Chronic Murine Cytomegalovirus Infection. The Journal of Immunology.

$548 \quad 2006 ; 177(1): 450-8$.

549 28. Karrer U, Wagner M, Sierro S, Oxenius A, Hengel H, Dumrese T, et al. Expansion of protective CD8+ 550 T-cell responses driven by recombinant cytomegaloviruses. J Virol. 2004;78(5):2255-64.

551 29. Holtappels R, Pahl-Seibert MF, Thomas D, Reddehase MJ. Enrichment of immediate-early 1 552 (m123/pp89) peptide-specific CD8 T cells in a pulmonary CD62L(lo) memory-effector cell pool during 553 latent murine cytomegalovirus infection of the lungs. J Virol. 2000;74(24):11495-503.

554 30. Holtappels R, Thomas D, Podlech J, Reddehase MJ. Two antigenic peptides from genes m123 and 555 m164 of murine cytomegalovirus quantitatively dominate CD8 T-cell memory in the H-2d haplotype. J 556 Virol. 2002;76(1):151-64.

557 31. Sylwester AW, Mitchell BL, Edgar JB, Taormina C, Pelte C, Ruchti F, et al. Broadly targeted human 558 cytomegalovirus-specific CD4+ and CD8+ T cells dominate the memory compartments of exposed 559 subjects. J Exp Med. 2005;202(5):673-85. 
560 32. Cicin-Sain L, Sylwester AW, Hagen SI, Siess DC, Currier N, Legasse AW, et al. Cytomegalovirus-

561 specific T cell immunity is maintained in immunosenescent rhesus macaques. Journal of immunology.

$562 \quad 2011 ; 187(4): 1722-32$.

563 33. Borkner L, Sitnik KM, Dekhtiarenko I, Pulm AK, Tao R, Drexler I, et al. Immune Protection by a

564 Cytomegalovirus Vaccine Vector Expressing a Single Low-Avidity Epitope. Journal of immunology. $565 \quad 2017 ; 199(5): 1737-47$.

566 34. Dekhtiarenko I, Ratts RB, Blatnik R, Lee LN, Fischer S, Borkner L, et al. Peptide Processing Is Critical 567 for T-Cell Memory Inflation and May Be Optimized to Improve Immune Protection by CMV-Based Vaccine 568 Vectors. PLoS pathogens. 2016;12(12):e1006072.

569 35. Tsuda Y, Caposio P, Parkins CJ, Botto S, Messaoudi I, Cicin-Sain L, et al. A replicating 570 cytomegalovirus-based vaccine encoding a single Ebola virus nucleoprotein CTL epitope confers 571 protection against Ebola virus. PLoS neglected tropical diseases. 2011;5(8):e1275.

572 36. Tsuda Y, Parkins CJ, Caposio P, Feldmann F, Botto S, Ball S, et al. A cytomegalovirus-based vaccine 573 provides long-lasting protection against lethal Ebola virus challenge after a single dose. Vaccine. $574 \quad 2015 ; 33(19): 2261-6$.

575 37. Zheng X, Oduro JD, Boehme JD, Borkner L, Ebensen T, Heise U, et al. Mucosal CD8+ T cell responses 576 induced by an MCMV based vaccine vector confer protection against influenza challenge. PLoS pathogens. 577 2019;15(9):e1008036.

578 38. Hirsl L, Brizic I, Jenus T, Juranic Lisnic V, Reichel JJ, Jurkovic S, et al. Murine CMV Expressing the 579 High Affinity NKG2D Ligand MULT-1: A Model for the Development of Cytomegalovirus-Based Vaccines. 580 Front Immunol. 2018;9:991.

581 39. Slavuljica I, Busche A, Babic M, Mitrovic M, Gasparovic I, Cekinovic D, et al. Recombinant mouse 582 cytomegalovirus expressing a ligand for the NKG2D receptor is attenuated and has improved vaccine 583 properties. The Journal of clinical investigation. 2010;120(12):4532-45. 
584 40. Snyder CM, Allan JE, Bonnett EL, Doom CM, Hill AB. Cross-presentation of a spread-defective 585 MCMV is sufficient to prime the majority of virus-specific CD8+ T cells. PloS one. 2010;5(3):e9681.

586 41. Cicin-Sain L, Bubic I, Schnee M, Ruzsics Z, Mohr C, Jonjic S, et al. Targeted deletion of regions rich 587 in immune-evasive genes from the cytomegalovirus genome as a novel vaccine strategy. J Virol. $588 \quad 2007 ; 81(24): 13825-34$.

589 42. Mohr CA, Arapovic J, Mühlbach H, Panzer M, Weyn A, Dölken L, et al. A spread-deficient 590 cytomegalovirus for assessment of first-target cells in vaccination. J Virol. 2010;84(15):7730-42.

591 43. Tamura M, Kuwano K, Kurane I, Ennis FA. Definition of amino acid residues on the epitope 592 responsible for recognition by influenza $\mathrm{A}$ virus $\mathrm{H} 1$-specific, $\mathrm{H} 2$-specific, and $\mathrm{H} 1$ - and $\mathrm{H} 2$-cross-reactive 593 murine cytotoxic T-lymphocyte clones. J Virol. 1998;72(11):9404-6.

594 44. Morabito KM, Ruckwardt TR, Redwood AJ, Moin SM, Price DA, Graham BS. Intranasal 595 administration of RSV antigen-expressing MCMV elicits robust tissue-resident effector and effector 596 memory CD8+ T cells in the lung. Mucosal immunology. 2017;10(2):545-54.

597 45. Chaudhry MZ, Messerle M, Cicin-Sain L. Construction of Human Cytomegalovirus Mutants with 598 Markerless BAC Mutagenesis. Methods in molecular biology. 2021;2244:133-58.

599 46. Dag F, Dolken L, Holzki J, Drabig A, Weingartner A, Schwerk J, et al. Reversible silencing of 600 cytomegalovirus genomes by type I interferon governs virus latency. PLoS pathogens. $601 \quad 2014 ; 10(2): \mathrm{e} 1003962$.

602 47. Chaudhry MZ, Eschke K, Grashoff M, Abassi L, Kim Y, Brunotte L, et al. SARS-CoV-2 Quasispecies 603 Mediate Rapid Virus Evolution and Adaptation. bioRxiv. 2020:2020.08.10.241414.

604 48. Bertoglio F, Meier D, Langreder N, Steinke S, Rand U, Simonelli L, et al. SARS-CoV-2 neutralizing 605 human recombinant antibodies selected from pre-pandemic healthy donors binding at RBD-ACE2 606 interface. 2020:2020.06.05.135921. 
607 49. Welten SPM, Redeker A, Toes REM, Arens R. Viral Persistence Induces Antibody Inflation without 608 Altering Antibody Avidity. J Virol. 2016;90(9):4402-11.

609 50. Madhun AS, Akselsen PE, Sjursen H, Pedersen G, Svindland S, Nostbakken JK, et al. An adjuvanted 610 pandemic influenza H1N1 vaccine provides early and long term protection in health care workers. Vaccine. $6112010 ; 29(2): 266-73$.

612 51. Kleine-Weber H, Elzayat MT, Wang L, Graham BS, Müller MA, Drosten C, et al. Mutations in the 613 Spike Protein of Middle East Respiratory Syndrome Coronavirus Transmitted in Korea Increase Resistance 614 to Antibody-Mediated Neutralization. J Virol. 2019;93(2).

615 52. Hoffmann M, Arora P, Groß R, Seidel A, Hörnich B, Hahn A, et al. SARS-CoV-2 variants B.1.351 and 616 B.1.1.248: Escape from therapeutic antibodies and antibodies induced by infection and vaccination. $617 \quad 2021: 2021.02 .11 .430787$.

618 53. Berger Rentsch M, Zimmer G. A vesicular stomatitis virus replicon-based bioassay for the rapid 619 and sensitive determination of multi-species type I interferon. PloS one. 2011;6(10):e25858.

620 54. Blazejewska P, Koscinski L, Viegas N, Anhlan D, Ludwig S, Schughart K. Pathogenicity of different 621 PR8 influenza A virus variants in mice is determined by both viral and host factors. Virology. $622 \quad 2011 ; 412(1): 36-45$.

623 55. Bubić I, Wagner M, Krmpotić A, Saulig T, Kim S, Yokoyama WM, et al. Gain of virulence caused by 624 loss of a gene in murine cytomegalovirus. J Virol. 2004;78(14):7536-44.

625 56. Cardin RD, Abenes GB, Stoddart CA, Mocarski ES. Murine cytomegalovirus IE2, an activator of 626 gene expression, is dispensable for growth and latency in mice. Virology. 1995;209(1):236-41.

627 57. Capel PJ, Gerlag PG, Hagemann JF, Koene RA. The effect of 2-mercaptoethanol on IgM and IgG 628 antibody activity. J Immunol Methods. 1980;36(1):77-80. 
629 58. Suwannalai P, Scherer HU, van der Woude D, loan-Facsinay A, Jol-van der Zijde CM, van Tol MJ, 630 et al. Anti-citrullinated protein antibodies have a low avidity compared with antibodies against recall 631 antigens. Ann Rheum Dis. 2011;70(2):373-9.

632 59. Ynga-Durand MA, Dekhtiarenko I, Cicin-Sain L. Vaccine Vectors Harnessing the Power of 633 Cytomegaloviruses. Vaccines (Basel). 2019;7(4).

634 60. Murphy K, Travers P, Walport M, Janeway C. Janeway's immunobiology. New York: Garland 635 Science; 2008.

636 61. Bongard N, Le-Trilling VTK, Malyshkina A, Rückborn M, Wohlgemuth K, Wensing I, et al. 637 Immunization with a murine cytomegalovirus based vector encoding retrovirus envelope confers strong 638 protection from Friend retrovirus challenge infection. PLoS pathogens. 2019;15(9):e1008043.

639 62. Trsan T, Busche A, Abram M, Wensveen FM, Lemmermann NA, Arapovic M, et al. Superior 640 induction and maintenance of protective CD8 T cells in mice infected with mouse cytomegalovirus vector 641 expressing RAE-1gamma. Proc Natl Acad Sci U S A. 2013;110(41):16550-5.

642 63. Slavuljica I, Krmpotic A, Jonjic S. Manipulation of NKG2D ligands by cytomegaloviruses: impact on 643 innate and adaptive immune response. Front Immunol. 2011;2:85.

644 64. Klyushnenkova EN, Kouiavskaia DV, Parkins CJ, Caposio P, Botto S, Alexander RB, et al. A 645 cytomegalovirus-based vaccine expressing a single tumor-specific CD8+ T-cell epitope delays tumor 646 growth in a murine model of prostate cancer. Journal of immunotherapy (Hagerstown, Md : 1997). $647 \quad 2012 ; 35(5): 390-9$.

648 65. Seckert CK, GriessI M, Buttner JK, Scheller S, Simon CO, Kropp KA, et al. Viral latency drives 649 'memory inflation': a unifying hypothesis linking two hallmarks of cytomegalovirus infection. Medical 650 microbiology and immunology. 2012;201(4):551-66. 
651 66. Hansen SG, Marshall EE, Malouli D, Ventura AB, Hughes CM, Ainslie E, et al. A live-attenuated 652 RhCMV/SIV vaccine shows long-term efficacy against heterologous SIV challenge. Sci Transl Med. 653 2019;11(501).

Figure Legends

Figure 1. Generation of recombinant MCMV vectors.

657 (A-B) Schematic images of the recombinant MCMV vector genome. (A) The HA gene of IAV PR8 658 was inserted along with minimal hMIEP in the m157 locus. (B) The SARS-CoV-2 spike ORF was 659 inserted in place of ie2. (C-D) Western blots of purified virus stocks of MCMVS, MCMV ${ }^{\mathrm{HA}}$ and 660 MCMVWT $^{\text {WT }}$ were performed with antibodies against (C) IAV HA or (D) the SARS CoV-2 S. As 661 controls we used (C) IE1 or (D) MCK-2 proteins of MCMV.

Figure 2. Immunization with $M C M V^{S}$ and $M C M V^{H A}$ elicits antigen-specific and neutralizing humoral responses

(A-E) BALB/c mice were infected with $2 \times 10^{5}$ PFU of $M C M V$ s via the i.p. route. Collected sera were tested for antigen-specific responses and neutralization capacity. (A) $\mathrm{EC}_{50}$ of $\lg \mathrm{G}$ isotypes specific for S1-S2 or RBD. Each symbol indicates an individual mouse, means from individual time points

667 are connected with lines. (B) Pseudovirus neutralization capacity (pVNT) against the SARS-CoV$6682 \mathrm{~S}$ WH01+D614G, B.1.1.7 and B.1.351 variants. The assay was performed in technical triplicates 669 and mean values for each mouse serum are shown, where each symbol represents the 670 percentage of neutralization of a mouse serum sample at $56 \mathrm{dpi}$. Values were calculated by 671 luciferase units. Lines connect the group averages for each serum dilution step. (C) Neutralization 672 capacity against SARS-CoV-2 $\left(\mathrm{VNT}_{50}\right)$ of total serum immunoglobulins (total $\lg$ ) or their lgG 673 fraction (lgG only) at indicated time points post immunization. Each symbol indicates sera from 674 one mouse and lines connect means for each time point. (D) Percentage of serum antibodies 
675 binding to the S protein (y axis), in the presence of increasing concentrations of NaSCN ( $\mathrm{x}$ axis) 676 and normalized to ELISA values in absence of NaSCN. Each line connects the average residual 677 binding at indicated molar concentrations of NaSCN. Error bars are standard deviations (SD). (E) 678 Percentage of residual antibodies binding to $S$ in the presence of $1 \mathrm{M} \mathrm{NaSCN}$. The assay was 679 performed in biological triplicates as in panel $D$ and data from indicated time points post 680 immunization were statistically compared by one-way ANOVA. ${ }^{* * *} p<0.001(F)$ Titers of HA681 specific antibodies at 28 dpi with $\mathrm{MCMV}^{\mathrm{HA}}$ or MCMV ${ }^{\mathrm{IVL}}$. Data were pooled from two independent 682 experiments. Long horizontal lines indicate means. Mann-Whitney $U$ test was used for statistical 683 analysis ${ }^{* *} p<0.001$.

Figure 3. MCMVHA immunization induces robust immune protection, but poor IVL-specific 685 CD8+ T-cell response

(A-B) C57BL/6 female mice were immunized with $2 \times 10^{5} \mathrm{PFU}$ of $\mathrm{MCMV}^{\mathrm{HA}}$ or $\mathrm{MCMV}^{\mathrm{Am} 157}$ virus via 687 the f.p. route. After 21 days, mice were challenged with IAV (100 HU). (A) Body weight loss and (B) survival rates were measured. (C-G) BALB/C mice were infected with $2 \times 10^{5}$ PFU of MCMVHA or MCMVIVL via the i.p. route. (C) Blood leukocytes were isolated and stimulated in vitro with IVL690 peptide for $6 \mathrm{~h}$ and analyzed by intracellular cytokine staining (ICCS) in flow cytometry at indicated 691 dpi. Percentages and cell counts of IVL-specific CD8 ${ }^{+} \mathrm{T}$ cells in peripheral blood are shown as 692 averages +/- SD ( $n=6-10)$ (D-G) Immunized mice were challenged with IAV (1100 FFU, i.n.) at >

6933 months p.i. Blood leukocytes were in vitro stimulated with the IVL-peptide for $6 \mathrm{~h}$ and analyzed 694 by ICCS in flow cytometry on day 8 post challenge. Each symbol represents an individual mouse 695 sample. (E) IAV titers measure by focus-forming assay (FFA) in the lungs on day 5 post challenge. Each symbol represents an individual mouse. (F) Average body weight loss upon IAV challenge

697 at indicated time points $(n=6-9)$. (G) Titers of HA-specific antibodies in serum samples on day 5 698 after IAV challenge. Titers were detected by HA inhibition assay, $n=6-9$. Each symbol represents 
699

700

701

702

703

704

705

706

707

708

709

710

711

712

713

714

715

716

717

718

an individual mouse. All of above data are pooled data from two independent experiments. MannWhitney $U$ test were used for statistical analysis ${ }^{* *} p<0.01,{ }^{* * *} p<0.001,{ }^{* \star *} p<0.0001$.

Figure 4. Humoral immunity elicited by MCMV ${ }^{\mathrm{HA}}$ protects against IAV challenge.

$\mathrm{JHT}$ and BALB/c mice were immunized with $2 \times 10^{5}$ PFU of MCMVHA via the i.p. route. 120 days after immunization, mice were challenged with IAV (1100 FFU, i.n.). (A) Setup of the experiment.

(B) Titers of HA-specific antibody in serum samples on day 5 after IAV challenge determined by HAI. (C) IAV lung titers on day 5 post challenge. (D) Body weight loss upon IAV challenge. All data are pooled data from two independent experiments. Each symbol represents an individual mouse sample. Horizontal lines indicate means and error bars indicate standard error. Two-Way ANOVA for Fig. 5D or Mann-Whitney $U$ test for Fig. 5B and 5C were used for statistical analysis. ${ }^{* *} p<0.01,{ }^{* * *} p<0.001,{ }^{* * *} p<0.0001$.

\section{Table Legends}

Table 1. $\mathrm{VNT}_{50}$ of $\mathrm{MCMV}^{\mathrm{S}}$ immunized mouse serum samples against SARS-CoV-2 or pseudotyped VSV-S.

The table indicates average $\mathrm{VNT}_{50}$ or $\mathrm{pVNT}_{50}$ values against SARS-CoV-2 or pseudotyped VSVS of serum samples collected from immunized mice at indicated time points. Neutralizing antibody titers were calculated by nonlinear IC50 regression analysis in GraphPad Prism 9. The indicated $\mathrm{VNT}_{50}$ or $\mathrm{pVNT}_{50}$ values denote the serum dilution that results in a $50 \%$ reduction of virus plaques or of VSV luciferase activity. 
A

B
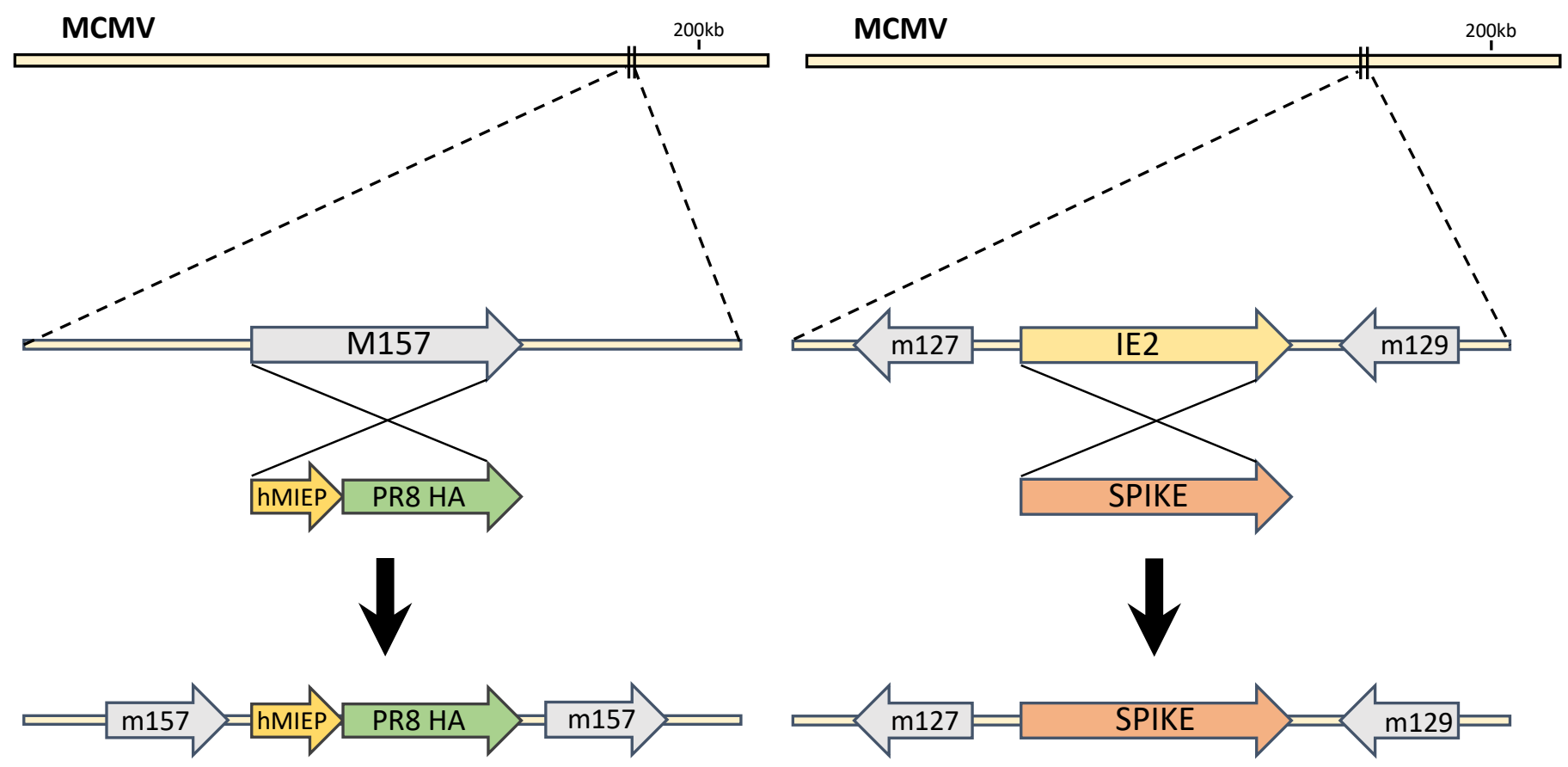

$\mathrm{MCMV}^{\mathrm{HA}}$

\section{$\mathrm{MCMV}^{\mathrm{S}}$}

C

D
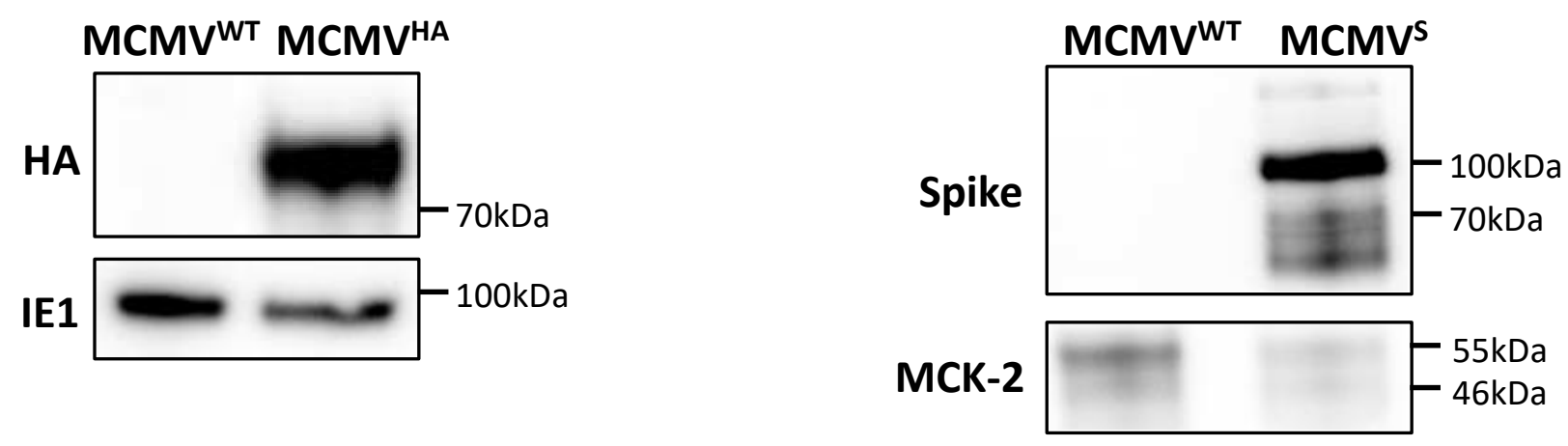
A

B
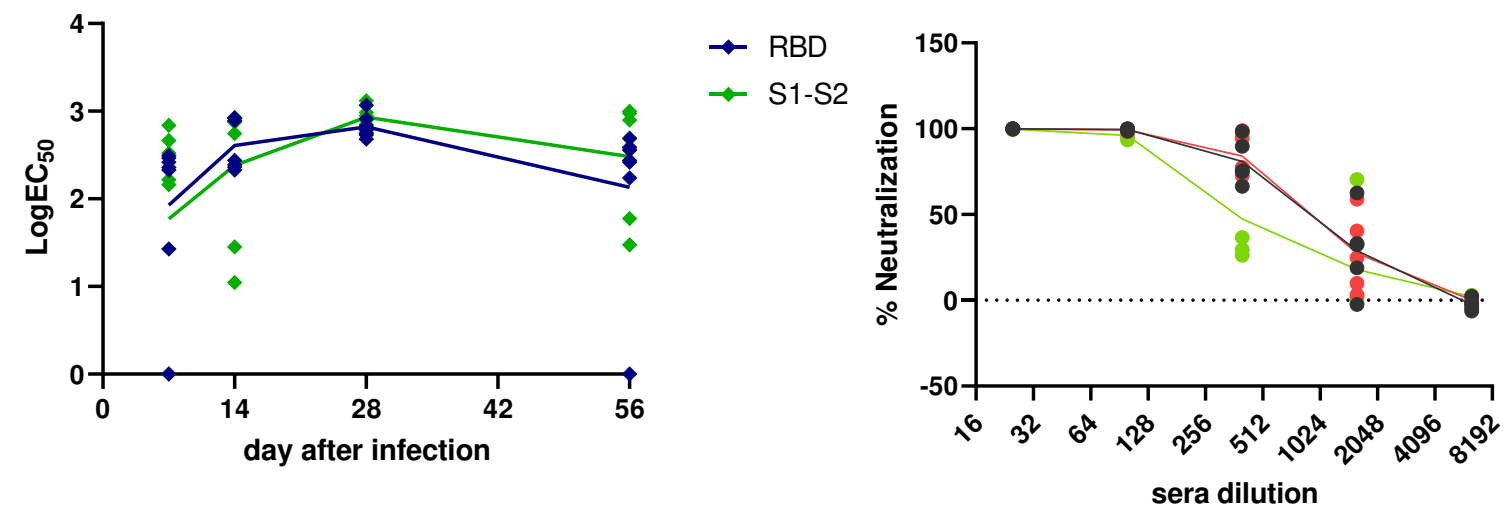

- $\mathrm{WH01+D614G}$

- B1.1.7

- B1.351

C
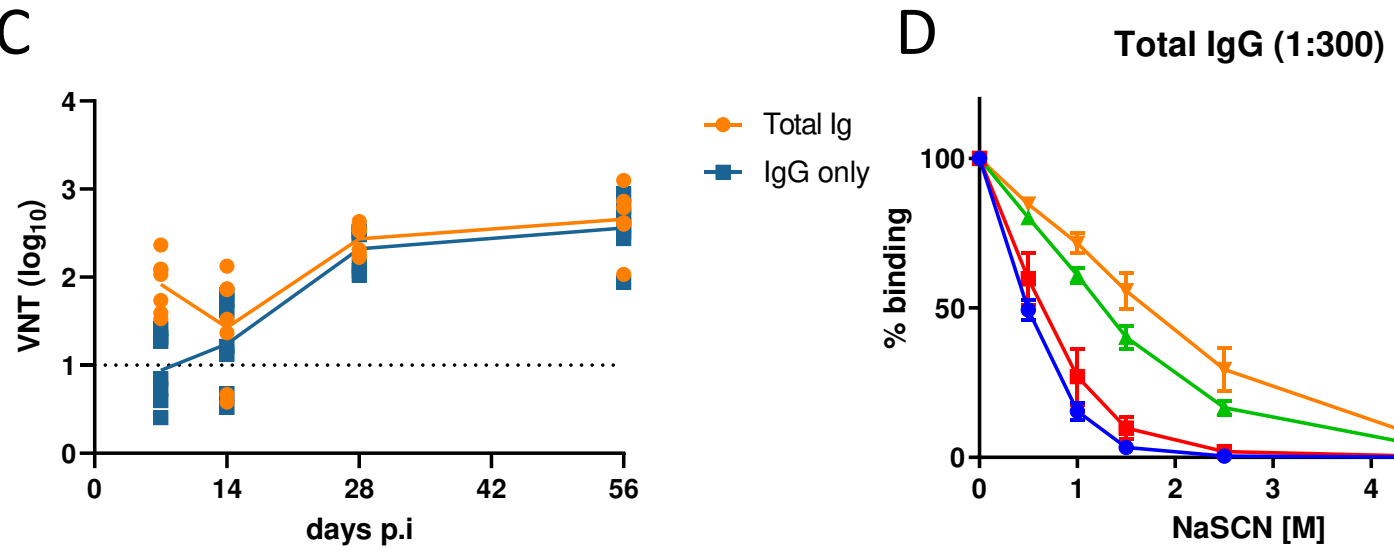

- Total lg
$-\quad$ IgG only

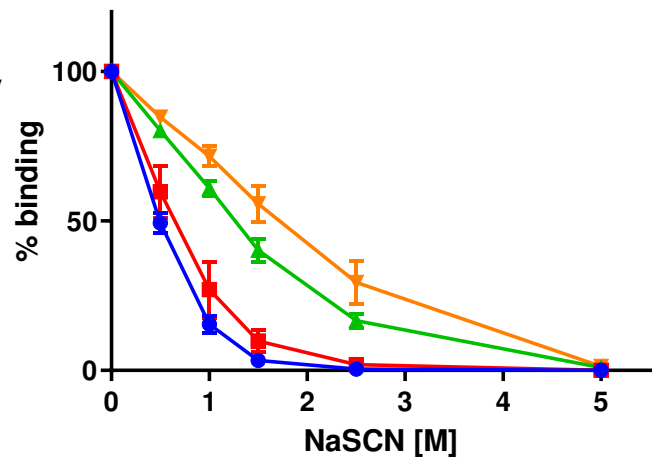

- $7 \mathrm{DPI}$

- $14 \mathrm{DPI}$

- $28 \mathrm{DPI}$

$756 \mathrm{DPI}$

E

F

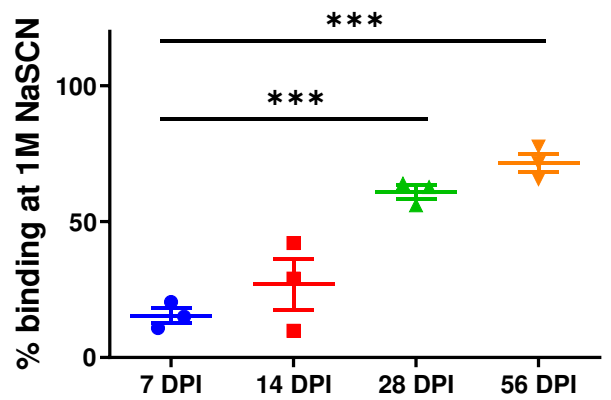

- $7 \mathrm{DPI}$

- $14 \mathrm{DPI}$

- $28 \mathrm{DPI}$

จ $56 \mathrm{DPI}$

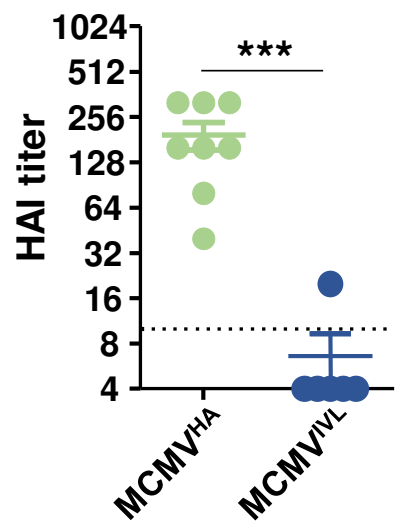


A

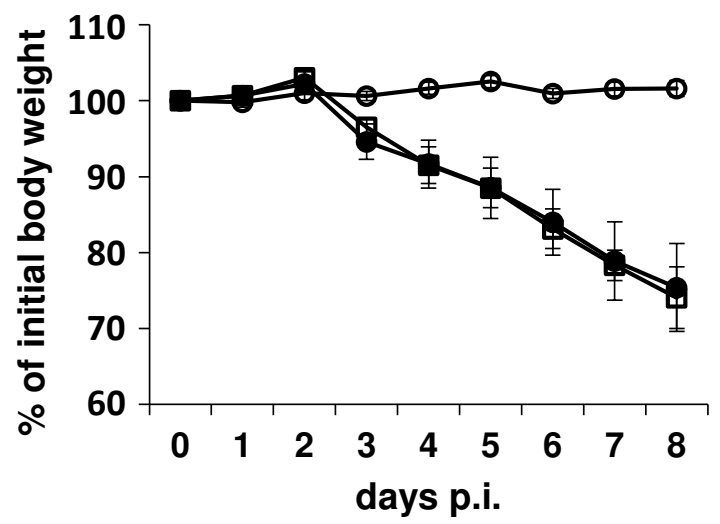

C
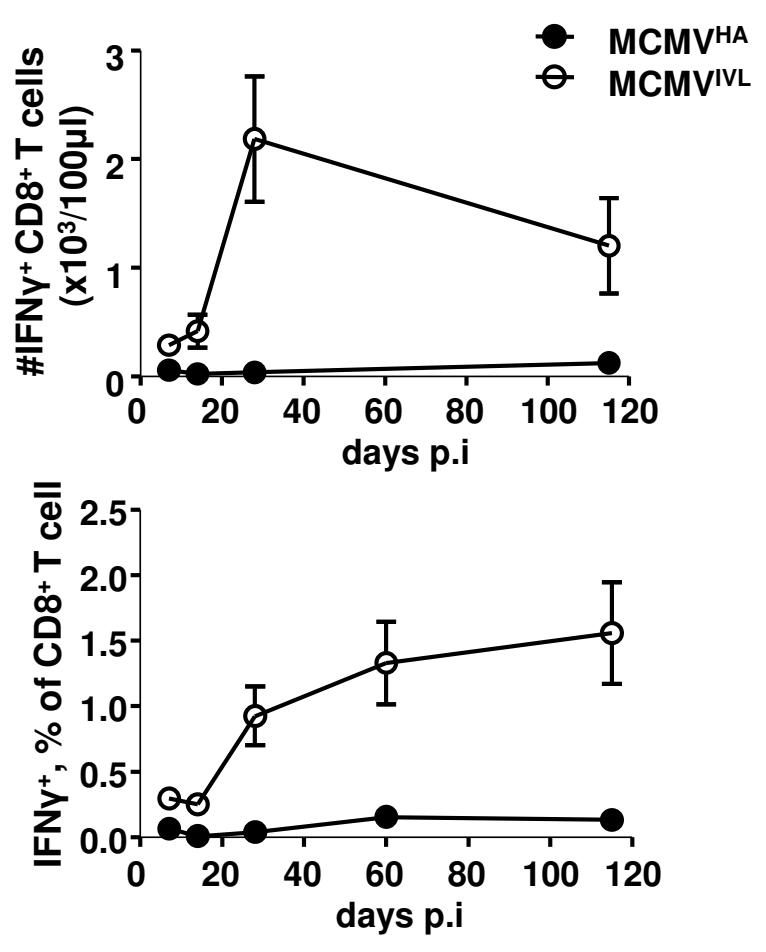

F

E

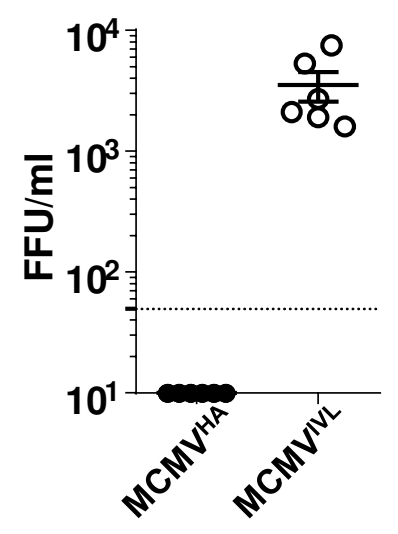

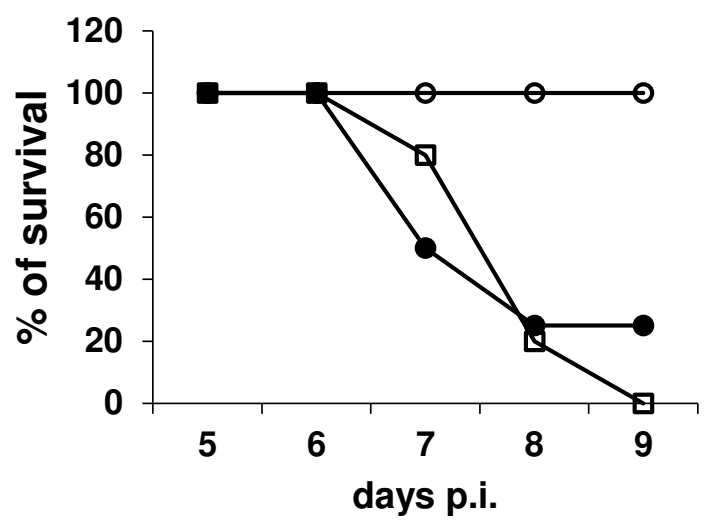

- MCMV-HA

$\rightarrow-M C M V d m 157$

$\rightarrow$ unimmune
D
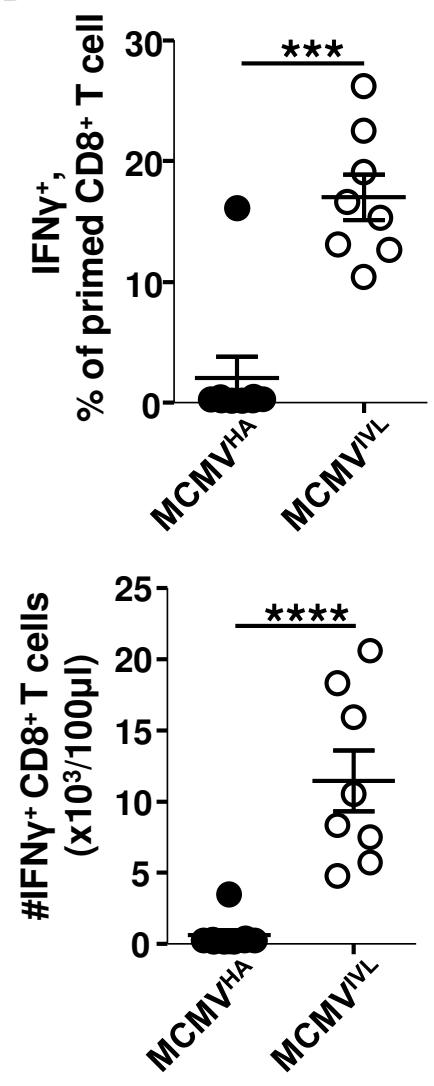

G

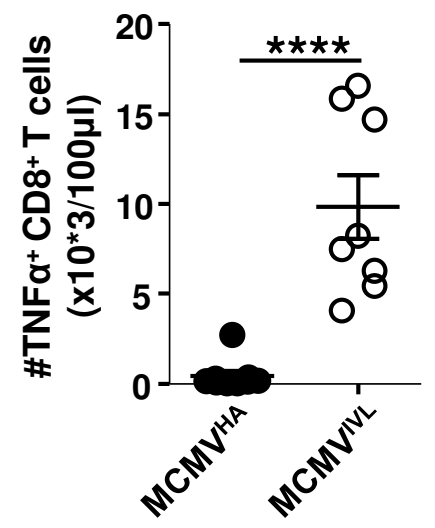


A
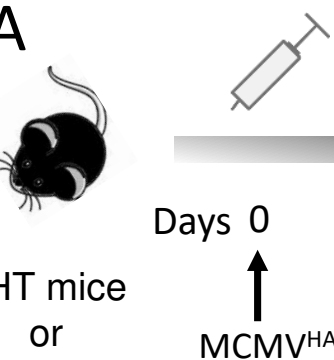

JHT mice

or

MCMVHA

$\mathrm{BALB} / \mathrm{c}$ immunization

Daily observation

Weight measurement

H

$120 \quad 125$

IAV challenge Sacrificed

Sample collection

B
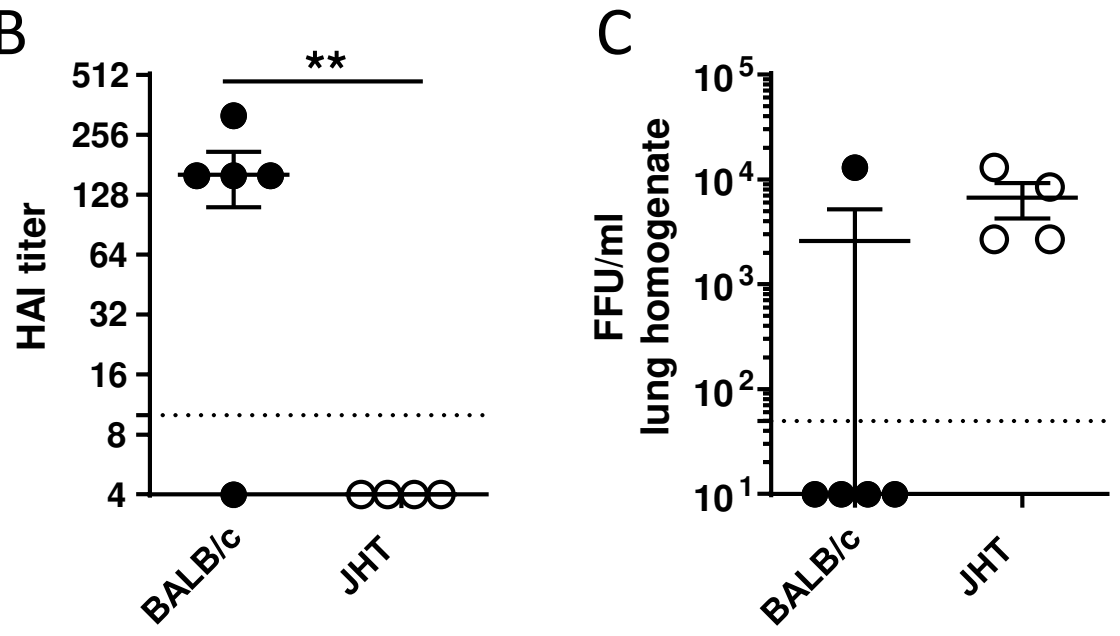

D

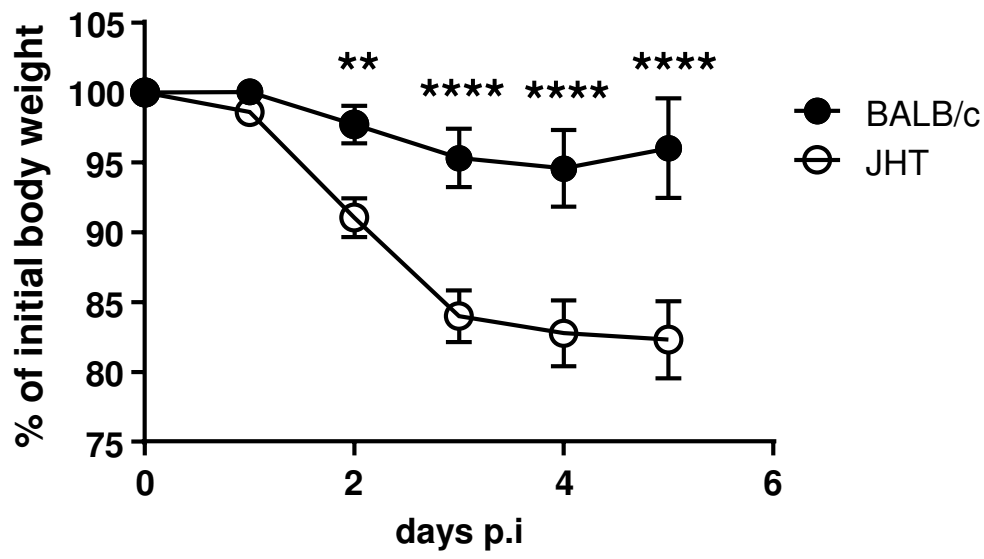




\section{Supplementary Files}

This is a list of supplementary files associated with this preprint. Click to download.

- Table1.xlsx

- SupplementaryFigure.pdf

- Supplementaryfigurelegends.pdf 